\title{
Estrogen Receptor $\alpha$ Participates to the Beneficial Effect of Red Wine Polyphenols in a Mouse Model of Obesity-Related Disorders
}

\author{
Daniela Leonetti ${ }^{1+}$, Raffaella Soleti ${ }^{1+}$, Nicolas Clere ${ }^{1}$, Luisa Vergori ${ }^{1}$, Caroline Jacques ${ }^{1}$, \\ Lucie Duluc ${ }^{1}$, Catherine Dourguia' ${ }^{1}$, Maria C. Martínez ${ }^{1}$ and \\ Ramaroson Andriantsitohaina ${ }^{1,2 *}$
}

'INSERM U1063, Stress Oxydant et Pathologies Métaboliques, Université d'Angers, Angers, France, ${ }^{2}$ Centre Hospitalier Universitaire d'Angers, Angers, France

\section{OPEN ACCESS}

Edited by: Bimal Malhotra,

Pfizer, USA

Reviewed by:

Philip Aaronson,

King's College London, UK

Geoffrey A. Head,

Baker IDI Heart and Diabetes Institute,

Australia

*Correspondence:

Ramaroson Andriantsitohaina ramaroson.andriantsitohaina@univ-

angers.fr

${ }^{\dagger}$ These authors have contributed equally to this work

Specialty section:

This article was submitted to Cardiovascular and Smooth Muscle Pharmacology,

a section of the journal

Frontiers in Pharmacology

Received: 18 October 2016

Accepted: 20 December 2016

Published: 10 January 2017

Citation:

Leonetti $D$, Soleti $R$, Clere $N$, Vergori $L$, Jacques $C$, Duluc $L$

Dourguia C, Martínez MC and Andriantsitohaina R (2017) Estrogen

Receptor a Participates to the Beneficial Effect of Red Wine Polyphenols in a Mouse Model of Obesity-Related Disorders.

Front. Pharmacol. 7:529. doi: 10.3389/fphar.2016.00529
Red wine polyphenol extracts (polyphenols) ameliorate cardiovascular and metabolic disorders associated with obesity. Previously, we demonstrated that the alpha isoform of estrogen receptor $(E R \alpha)$ triggers the vascular protection of polyphenols. Here, we investigated the contribution of ER $\alpha$ on the effects of polyphenols on cardiovascular and metabolic alterations associated with obesity. We used ovariectomized wild type or ER $\alpha$-deficient mice receiving standard (SD) or western (WD) diets, or SD and WD containing polyphenols (SD+polyphenols and WD+polyphenols, respectively) over a 12-week period. Body weight was measured during treatment. Echocardiography examination was performed before sacrifice. Blood and tissues were sampled for biochemical and functional analysis with respect to nitric oxide $(\mathrm{NO} \bullet)$ and oxidative stress. Vascular reactivity and liver mitochondrial complexes were analyzed. In WDfed mice, polyphenols reduced adiposity, plasma triglycerides and oxidative stress in aorta, heart, adipose and liver tissues and enhanced NO production in aorta and liver. ER $\alpha$ deletion prevented or reduced the beneficial effects of polyphenols, especially visceral adiposity, aortic and liver oxidative stresses and $\mathrm{NO} \bullet$ bioavailability. ER $\alpha$ deletion, however, had no effect on polyphenol's ability to decrease the fat accumulation and oxidative stress of subcutaneous adipose tissue. Also, ER $\alpha$ deletion did not modify the decrease of ROS levels induced by polyphenols treatment in the visceral adipose tissue and heart from WD-fed mice. Dietary supplementation of polyphenols remarkably attenuates features of metabolic syndrome; these effects are partially mediated by $E R \alpha$-dependent mechanisms. This study demonstrates the therapeutic potential of this extract in metabolic and cardiovascular alterations linked to excessive energy intake.

Keywords: estrogen receptor $\alpha$, metabolic disorders, obesity, polyphenols, vascular disorders

\footnotetext{
Abbreviations: 5-HT, serotonin; A, amplitude; Ach, acetylcholine; AMPK, AMP-activated protein kinase; ANOVA, analysis of variance; A.U., arbitrary units; bw, body weight; CDK, cyclin-dependent kinase; CMH, 1-hydroxy-3-methoxycarbonyl2,2,5,5-tetramethylpyrrolidine; COI, cardiac output index; CS, citrate synthase; DETC, Fe2+diethyldithiocarbamate; EF, ejection fraction; EGCG, epigallocatechin-3-gallate; EPR, electron paramagnetic resonance; ERK, extracellular signalregulated kinase; ER $\alpha$, estrogen receptor alpha; KO, Knock Out; LVEDD, diastolic left ventricular dimension; LVSED, systolic left ventricular dimension; NF- $\mathrm{B}$, nuclear factor kappa-light-chain-enhancer of activated $\mathrm{B}$ cells; $\mathrm{NO}^{\bullet}$, nitric oxide; OVX, ovariectomized; PGC- $1 \alpha$, peroxisome proliferator-activated receptor gamma coactivator-1 $\alpha$; PPAR $\gamma$, peroxisome proliferator-activated receptors $\gamma$; PSS, physiological salt solution; ROS, reactive oxygen species; SD, standard diet; WD, western diet; WT, wild type.
} 


\section{INTRODUCTION}

Obesity is defined as abnormal or excessive fat accumulation associated with an increased risk of premature death due to an increased incidence of metabolic diseases such as insulin resistance, type 2 diabetes, dyslipidemia, non-alcoholic fatty liver disease and coronary heart disease. Based on epidemiological studies reporting a greater reduction in cardiovascular risk and metabolic disorders associated with polyphenol-rich diet, several dietary and pharmacological approaches have been proposed to manage or prevent obesity and obesity-related diseases. Polyphenols are bioactive food compounds primarily present in fruits and vegetables and exert health benefits protecting against metabolic and cardiovascular disturbances (Andriantsitohaina et al., 2012). Polyphenols, in particular those derived from red wine, possess anti-aggregatory platelet activity, antioxidant and free radical scavenging properties (Curin et al., 2006; Pechanova et al., 2006), as well as lipidand lipoprotein-lowering effects (Curin et al., 2006). We have reported that red wine polyphenols (polyphenols) are powerful vasodilators through the generation of $\mathrm{NO}^{\bullet}$ and can act on the expression of protective genes of the cardiovascular system (Andriambeloson et al., 1997). Importantly, in a rat model of insulin-resistance, polyphenols prevent hypertension, cardiac hypertrophy as well as ROS production in aorta and heart (Bernátová et al., 2002; Al-Awwadi et al., 2005). Moreover, in a context of obesity, polyphenols ameliorate glucose and lipid metabolism, cardiac function, decrease peripheral resistance and improve endothelium-dependent relaxation by enhancing $\mathrm{NO}^{\bullet}$ bioavailability (Agouni et al., 2009).

Among the different classes of polyphenolic compounds present in red wine, anthocyanins and oligomeric condensed tannins exhibit pharmacological profiles comparable with total extracts in terms of endothelial-dependent $\mathrm{NO}^{\bullet}$ mediated vasodilatation (Andriambeloson et al., 1998). Among anthocyanins identified in wine, only delphinidin causes endothelium-dependent relaxation, however, it is slightly less potent than total extract (Andriambeloson et al., 1998).

A growing body of evidence demonstrates that estrogenic signaling has an important role in obesity development (Musatov et al., 2007; Xu et al., 2011). Indeed, $17 \beta$-estradiol acts on the $\alpha$ isoform of receptor $(\mathrm{ER} \alpha)$ and protects against obesityrelated diseases (Musatov et al., 2007; Xu et al., 2011). Of note, $\mathrm{ER} \alpha$ has been identified as one of the key receptors transducing vascular effects exerted by polyphenols, particularly for delphinidin (Chalopin et al., 2010). These compounds interact directly with $\mathrm{ER} \alpha$, activating molecular pathways including Src, ERK1/2, eNOS, leading to endothelial $\mathrm{NO}^{\bullet}$ production, and consequently vasorelaxation (Chalopin et al., 2010).

Based on these observations, the present study was designed to investigate the contribution of $\mathrm{ER} \alpha$ to the effect of polyphenols in an experimental model of obesity and related metabolic disorders using $\mathrm{ER} \alpha \mathrm{WT}$ or $\mathrm{KO}$ mice. In order to avoid the cofounding effect of circulating estrogens on the effect of polyphenols, known to possess structural similarities with estrogens (Bowers et al., 2000; Chalopin et al., 2010), mice were OVX. Animals were fed with a SD or a WD or
$\mathrm{SD}$ and WD containing polyphenols (SD+polyphenols and WD+polyphenols, respectively). Particular emphasis has been placed on body weight and fat deposition, glucose and lipid metabolism, cardiac and vascular functions, tissue $\mathrm{NO}^{\bullet}$ and $\mathrm{ROS}$ generation and hepatic mitochondrial function.

\section{MATERIALS AND METHODS}

\section{Products}

Polyphenols (exGrape ${ }^{\circledR}$ TOTAL) were obtained from Grap'Sud (Cruviers-Lascours, France). The phenolic composition of dry powder in mg/g was: 2.72 hydroxybenzoic acids (gallic acid and ethyl gallate), 315.60 flavan-3-ols (catechins, epicatechins, B1, B2, B3, B4, galloyl, (epi)cat-epigallocatechin dimers, trimer), 0.81 stilbenes (trans-resveratrol, $\varepsilon$-viniferin, cis-resveratrol), $0.58 \mathrm{mg} / \mathrm{g}$ dihydroflavonol (astilbin), 3.62 hydroxycinnamic acids (caftaric acid, coutaric acid, caffeic acid, fertaric acid, cumaric acid), 15.10 flavonols (myricetin 3-O-glucuronide, myricetin 3-O-glucoside, quercetin 3-O-galactoside, quercetin 3 $\mathrm{O}$-glucuronide, quercetin 3-O-glucoside, laricitrin 3-O-glucoside, myricetin aglycone, syringetin glucoside, quercetin aglycone), 3.89 anthocyanins [(epi)cat-malvidin 3-O-glucoside, delphinidin 3-O glucoside, cyanidin 3-O-glucoside, petunidin 3-O-glucoside, (malvidin + peonidin] 3-O-glucoside, pyranomalvidin pyruvic acid, malv-ethyl-(epi)catechin, (malvidin + peonidin) acetyl glucoside, pyranomalvidin 3-O-coumaroyl glucoside, petunidin 3-O-coumaroyl glucoside, (malvidin + peonidin) 3-O-coumaroyl glucoside, pyranomalvidin vinyl catechol, pyranomalvidin vinyl phenol).

Polyphenols were mixed into a chow supplied in powder form at $150 \mathrm{mg} / \mathrm{kg}$. By taking into account that the weight of the mouse is, in average, $22 \mathrm{~g}$ (please Table 1) and that each mouse eats $4 \mathrm{~g}$ of chow per day, the mouse consumes $0.6 \mathrm{mg}$ of polyphenols per day. Thus, the mouse received a dose of polyphenols of $27.3 \mathrm{mg} / \mathrm{kg} /$ day. This dose is consistent with our former studies (Diebolt et al., 2001; Baron-Menguy et al., 2007; Agouni et al., 2009; Chalopin et al., 2010, 2014) and is comparable to the concentration that produced maximal relaxation of mouse aortic rings ex vivo. This was also compatible with a human consumption of one to two glasses of red wine per day and was in the range of that shown to possess beneficial effects on oxidative damage in humans (Covas et al., 2010).

SD (U8960P version 0066) and WD (U8958P version 0052) as well as those containing polyphenols were obtained from SAFE (Augy, France) (Supplemental Table 1).

$\mathrm{SD}$ contains $5 \%$ of fat based on its composition in $\mathrm{g} / \mathrm{kg}$ which represents $12 \%$ calories of total diet. With regard to $\mathrm{WD}$, it contains $21.5 \%$ of fat in $\mathrm{g} / \mathrm{kg}$ that corresponds to $36.8 \%$ calories.

\section{Ethics Statement}

The local ethics committee ("Comité d'éthique en expérimentation animale Pays de la Loire") approved the animal protocol followed in the present study (CEEA.2011.40). This study was carried out in strict accordance with the 


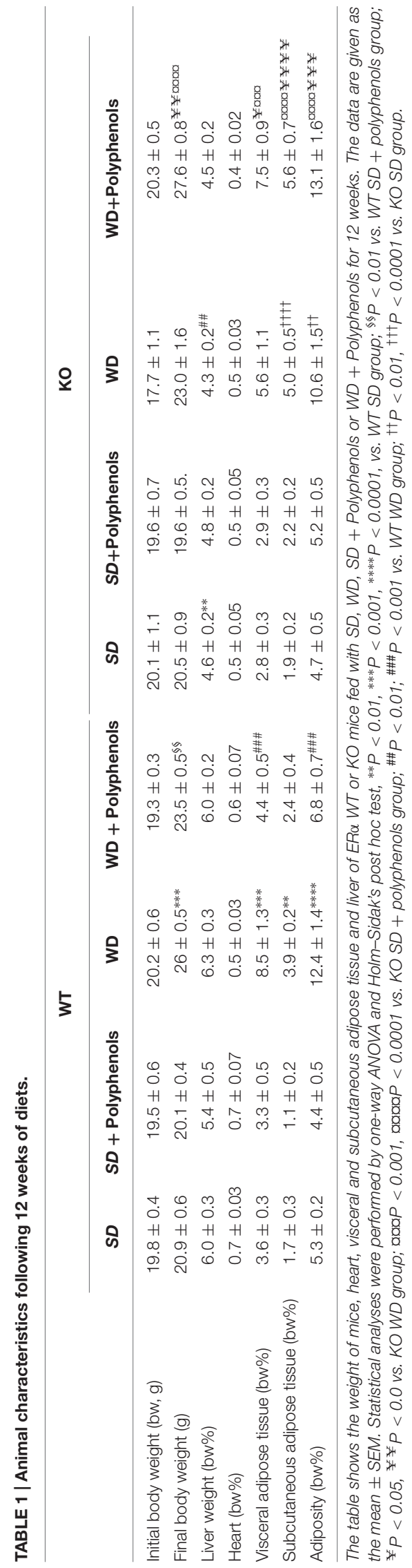

guidelines and authorization with French Ministry of Agriculture regulations based on European Community.

\section{Animals and Protocol Design}

Eight-week-old female $\mathrm{C} 57 \mathrm{bl} / 6 \mathrm{ER} \alpha \mathrm{WT}$ or KO mice were purchased from the Jackson Laboratories (Bar Harbor, ME) and maintained at $23 \pm 2^{\circ} \mathrm{C}$ under a $12 \mathrm{~h}$ light-dark cycle. Mice were OVX following a week of acclimation.

Mice were anesthetized using isoflurane $(5 \%$ in induction chamber, $2 \%$ in mask, flow of oxygen $1 \mathrm{~L}$ /minute). As an analgesic, buprenorphine $(0.1 \mathrm{mg} / \mathrm{kg}$ sc injection) was administered pre- and post-surgery. During and after surgery, mice were placed on heating pad.

After 7 days, both strains were randomly divided into four groups $\mathrm{SD}, \mathrm{WD}, \mathrm{SD}+$ polyphenols and $\mathrm{WD}+$ polyphenols during 12 weeks ( $n=7 /$ group). Mice were allowed ad libitum access to water and diets. Animal body weight was measured weekly. One week before sacrifice, mice were anesthetized for echocardiography examination. After treatment, mice were euthanized by gradient $\mathrm{CO}_{2}$ inhalation. First, we evaluated the efficiency of ovariectomy assessed by uterus atrophy. The comparison of uterus weight of OVX mice with uterus weight of non-OVX mice was performed. Only the animals showing uterus atrophy have been included in the study which explain why the final number of animals was different in each group (WT $\mathrm{SD} n=5$, WT SD +polyphenols $n=6$, WT WD $n=5$, WT $\mathrm{WD}+$ polyphenols $n=7, \mathrm{KO} \mathrm{SD} n=5, \mathrm{KO} \mathrm{SD}+$ polyphenols $n=5$, KO WD $n=4$, KO WD + polyphenols $n=5$ ). Then, blood, tissues and organs were sampled for biochemical and/or histological analysis.

\section{Biochemical Analyses}

Blood was collected by cardiac puncture at sacrifice and blood was centrifuged for $15 \mathrm{~min}$ at $950 \mathrm{~g}$ and room temperature to obtain plasma. Fasting glucose, triglycerides, total cholesterol, LDL-cholesterol and HDL-cholesterol were measured using Konelab $^{\mathrm{TM}} 20$ Clinical Chemistry Analyzer (Thermo Scientific, Waltham, MA, USA).

\section{Ex vivo Vascular Reactivity}

Mice aorta was dissected and placed in modified Krebs-Henseleit bicarbonate solution. Aortic rings were then mounted on a wire myograph (Danish MyoTechnology, Aarhus, Denmark) and filled with PSS, as previously described Chalopin et al. (2010). Endothelium-dependent vasodilatation in response to Ach ( $1 \mathrm{nmol} / \mathrm{L}$ to $10 \mathrm{mmol} / \mathrm{L}$; Sigma-Aldrich, St. Quentin, Fallavier, France) was studied in aortic rings with functional endothelium pre-contracted with the thromboxane A2 agonist (9,11-dideoxy11a, 9a-epoxymethanoprostaglandin F2-a, U46619) (SigmaAldrich) at $80 \%$ of their maximal response. Then, concentrationresponse curves were constructed by cumulative application of 5-HT ( $1 \mathrm{nmol} / \mathrm{L}$ to $10 \mu \mathrm{mol} / \mathrm{L}$; Sigma-Aldrich) to vessels with functional endothelium.

\section{Echocardiography Examination}

In vivo transthoracic echocardiography was performed using a VEVO 770 ultrasound machine from FUJIFILM Visualsonics 
(Toronto, ON, Canada) equipped with a $30-\mathrm{MHz}$ imaging transducer in mice anesthetized with isoflurane. Briefly, a twodimensional short axis view of the left ventricle was obtained in order to record M-mode tracings. LVEDD, LVSED and COI were evaluated.

\section{Nitric Oxide (NO ${ }^{\circ}$ ) and Reactive Oxygen Species (ROS) Determination by Electron Paramagnetic Resonance (EPR)}

Measurements were performed on a table-top $\mathrm{x}$-band spectrometer Miniscope (Magnettech, MS200, Berlin, Germany). Detection of $\mathrm{NO}^{\bullet}$ production in aorta, visceral and subcutaneous adipose tissues, heart and liver was performed using DETC (Sigma-Aldrich) as a spin trap, whereas ROS detection was performed using deferoxamine-chelated Krebs-Hepes solution containing CMH (500 $\mu \mathrm{mol} / \mathrm{L}$, Noxygen, Mainz, Germany), deferoxamine (25 $\mu \mathrm{mol} / \mathrm{L}$, Sigma-Aldrich), and DETC (5 $\mu \mathrm{mol} / \mathrm{L})$ (Agouni et al., 2009). Signal values are expressed in A.U. as data was corrected for total amplitude/mg weight of dried tissue, as previously described Agouni et al. (2009).

\section{Mitochondrial Enzyme Activities in Liver}

Activities of CS, complex I, II, and IV of mitochondria were spectrophotometrically measured on liver homogenates at $37^{\circ} \mathrm{C}$ and expressed in nmol of product formed per minute and per $\mathrm{mg}$ of protein in homogenates, as previously described Mingorance et al. (2012).

\section{Statistical Analysis}

Data were expressed as mean \pm SEM and $n$ represents the number of animals. The statistical software GraphPad Prism 7.0 (GraphPad Software Inc., San Diego, CA, USA) was used for data analysis. The difference between groups was performed by repeated measures two-way ANOVA for the evolution of body weight gain. For all the other experiments one-way ANOVA was applied. When ANOVA demonstrated a significant interaction between variables, post hoc analyses were performed by the multiple-comparison Holm-Sidak's test. $P<0.05$ was considered to be statistically significant.

\section{RESULTS}

\section{Effect of Polyphenols on Body and Organ Weight}

WD diet induced a time-dependent increase in body weight gain in WT mice compared to WT SD-fed mice $(P<0.0001)$ (Figure 1). Polyphenols did not modify body weight of WT mice fed with SD (Table 1) and it did not significantly reduce the body weight gain induced by WD compared to control. In $\mathrm{KO}$ mice, WD increased body weight gain $(P<0.0001)$ that was not significantly reduced upon polyphenol treatment.

In WT mice fed with WD, the increase of body weight was associated with higher visceral and subcutaneous adiposity compared to WT SD mice $(P=0.0002$ and $P=0.0045$,

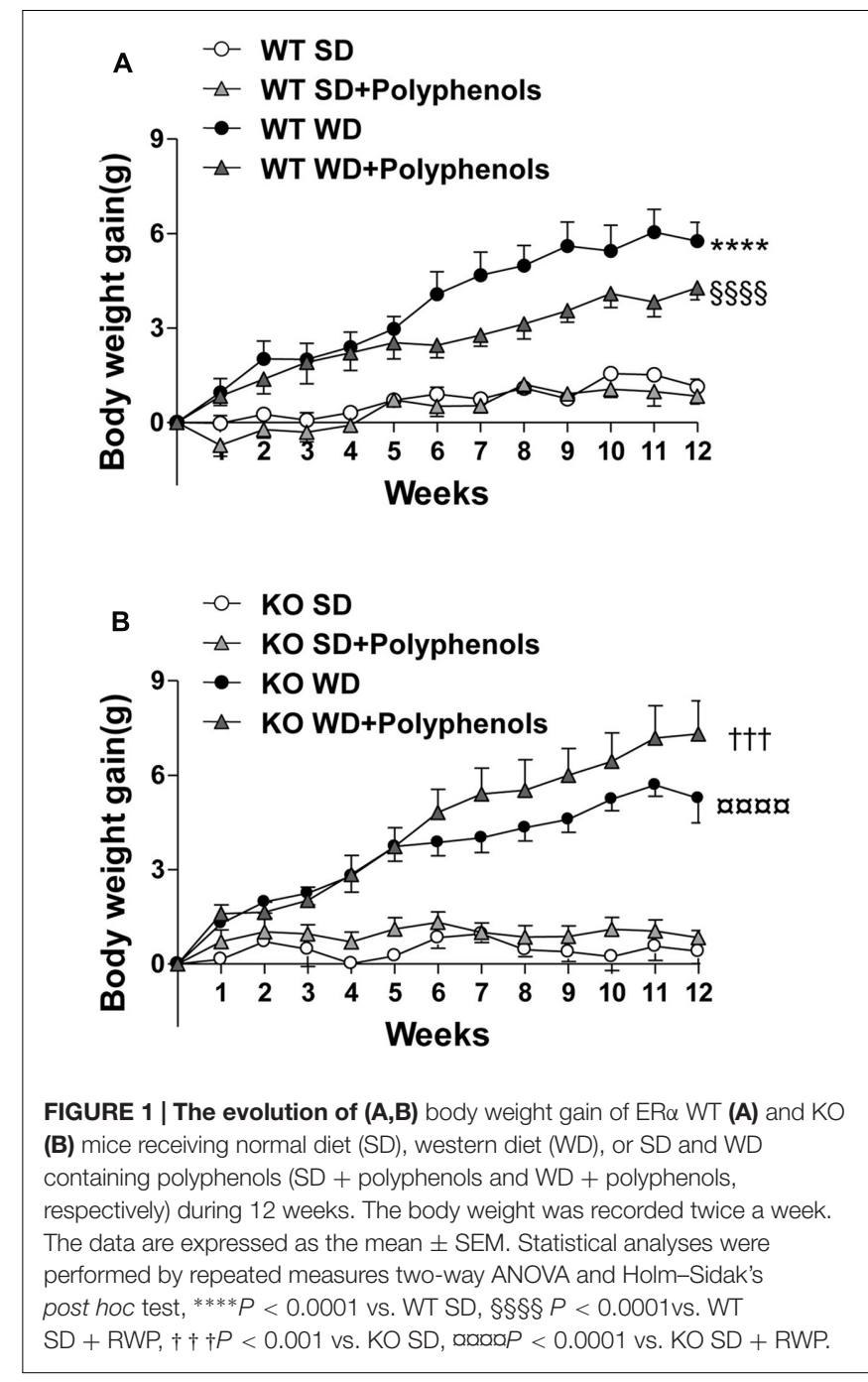

respectively) (Table 1). Interestingly, polyphenols decreased visceral $(P=0.0022)$ but not subcutaneous adiposity compared to WT WD mice. In mice lacking $\mathrm{ER} \alpha$, WD augmented subcutaneous adipose tissue weight $(P<0.0001)$. Polyphenols failed to modify the increase in weight of adipose tissues in mice lacking ER $\alpha$ treated with WD (Table 1).

Liver and heart weight was not modified upon WD and polyphenols supplementation in WT mice compared to SD-fed mice. Deletion of ER $\alpha$ decreased liver weight in mice fed with SD and WD $(P=0.0053$ and $P=0.0041$, respectively) compared to WT groups. Polyphenols had no effect on both liver and heart weight.

Altogether, these data show that the ability of polyphenols to reduce adiposity requires the presence of $\mathrm{ER} \alpha$.

\section{Effect of Polyphenols on Biochemical Plasma Parameters}

Plasma levels of glucose, triglycerides and cholesterol were greater in WT mice fed with WD compared to WT SD mice $(P=0.0025, P=0.0017$ and $P=0.00781$, respectively $)$ 
(Figure 2). HDL/LDL ratio (Figure 2) and insulin levels $(1.7 \pm 0.3$ vs. $1.8 \pm 0.6 \mathrm{ng} / \mathrm{dL})$ were not different in WT SD and WT WD mice.

Polyphenols normalized circulating levels of triglycerides $(P=0.0115)$ without affecting glycemia, cholesterolemia and HDL/LDL ratio in WT mice fed with WD.

Deletion of ER $\alpha$ increased HDL/LDL ratio in SD-fed mice compared to WT SD group $(P=0.0086)$, without modifications of other evaluated parameters.

WD significantly enhanced cholesterol levels in $\mathrm{KO}$ mice fed with polyphenols compared to those fed with SD plus polyphenols $(P=0.0202)$. Diet supplementation with polyphenols did not modify circulating parameters in $\mathrm{KO}$ mice.

Thus, $\mathrm{ER} \alpha$ was involved in the WD-induced hyperglycemia and hypertriglyceridemia and polyphenols did not further modify these parameters.

\section{Effects of Polyphenols on Aorta}

Both WD and polyphenols did not modify the endotheliumdependent relaxation to Ach in aortic rings from WT mice (Figure 3A). Deletion of $\mathrm{ER} \alpha$ did not affect relaxation to Ach compared WT mice (Figure 3B). In aortas from ER $\alpha$ $\mathrm{KO}$ mice, WD significantly reduced maximal response to Ach when compared to that from KO SD-fed mice $(P=0.0002)$. Polyphenols treatment did not significantly affect relaxation to Ach in aorta from both SD and WD-treated mice.

5-HT induced a concentration-dependent contraction in aortic rings from all groups of mice. 5-HT response was significantly decreased in mice receiving WD compared to those receiving $\mathrm{SD}(P=0.0001)$ (Figure $3 \mathrm{C})$. Polyphenols failed to improve the contractile response to 5-HT in WT mice independently of diet. Although not statistically significant, in the aortic rings from $\mathrm{KO}$ mice, the maximal contraction induced by 5 -HT was lower than those of WT mice. Neither WD nor polyphenols modified 5-HT-evoked responses in aorta for ER $\alpha$-deficient mice (Figure 3D).

\section{Effects of Polyphenols on Heart}

Echocardiographic analysis showed no significant modifications in heart structure and function, whatever the mouse strains and diets (Table 2).

\section{Effect of Polyphenols on Liver}

In WT mice, among all liver enzyme activities tested, WD only reduced complex II activity $(P=0.0092)$ (Figure 4C). Neither polyphenols nor deletion of $\mathrm{ER} \alpha$ had any effect on enzyme activity in SD-fed mice (Figures 4A,B,D). Complex II activity was greater in $\mathrm{KO}$ compared to WT mice fed with WD $(P=0.0026)$.

\section{Effect of Polyphenols on NO Production}

Aorta from WT mice fed with WD displayed a decrease in $\mathrm{NO}^{\bullet}$ production which was not significantly different from that observed in the SD group (Figure 5A). Polyphenols caused a significant $(P=0.00105)$ increase in $\mathrm{NO}^{\bullet}$ production in WT animals fed a WD, but not in those fed a $\mathrm{SD}$. $\mathrm{NO}^{\bullet}$ production in $\mathrm{ER} \alpha$-deficient mice fed with WD was lower than those of SD group $(P=0.0177$ ) (Figure 5A). Polyphenols did not modify $\mathrm{NO}^{\bullet}$ production in aortas taken from $\mathrm{KO}$ mice fed with both diets. These data provide evidence that $\mathrm{ER} \alpha$ is involved in the increase of $\mathrm{NO}^{\bullet}$ production induced by polyphenols.

In the heart, although not statistically significant, EPR measurement revealed a reduction of $45 \%$ in $\mathrm{NO}^{\bullet}$ production in WT mice fed with WD. Polyphenols did not significantly modify $\mathrm{NO}^{\bullet}$ production in WT in both $\mathrm{SD}$ and WD mice. In $\mathrm{ER} \alpha$-deficient mice, $\mathrm{NO}^{\bullet}$ production did not change independent of diet and polyphenol supplementation (Figure 5B).

$\mathrm{NO}^{\bullet}$ production in both visceral and subcutaneous adipose tissue was not significantly different, independent of both diets and strains (Figures 5C,D).

In $\mathrm{WT}$, WD significantly reduced hepatic $\mathrm{NO}^{\bullet}$ production (71\%) compared to SD-fed mice $(P<0.00001)$ (Figure 5E). Polyphenols reduced $\mathrm{NO}^{\bullet}$ levels (52\%) in SD-fed mice $(P=0.0006)$; however, it enhanced $\mathrm{NO}^{\bullet}$ production $(42 \%)$ in WD-fed mice $(P=0.0303)$. Deletion of $\mathrm{ER} \alpha$ profoundly decreased $\mathrm{NO}^{\bullet}$ production $(71 \%)$ in SD-fed mice $(P<0.00001)$. In $\mathrm{ER} \alpha$ deficient mice, WD did not significantly modify $\mathrm{NO}^{\bullet}$ production compared to SD-fed mice. In WD-fed ER $\alpha$ deficient mice, supplementation of polyphenols further reduced $\mathrm{NO}^{\bullet}$ production $(\sim 40 \%)(P=0.0238)$. These results suggest that polyphenols enhanced $\mathrm{NO}^{\bullet}$ bioavailability in the liver of WD-fed mice through an ER $\alpha$-dependent mechanism.

\section{Effect of Polyphenols on ROS Production}

In WT mice, ROS production was greater in aortas taken from WD-fed mice compared to SD group $(P=0.0001)$ (Figure 6A). Polyphenols did not modify oxidative stress in WT SD mice, but it completely prevented the increase of ROS induced by WD $(P=0.001)$. In $\mathrm{KO}$ mice, no changes in ROS production were observed (Figure 6B). These data suggest that the polyphenolinduced prevention of oxidative stress in aorta was dependent on $\mathrm{ER} \alpha$.

Reactive oxygen species production in the heart of WT mice fed with WD was greater than in SD mice $(P=0.0351)$ (Figure 6C). Interestingly, polyphenols decreased oxidative stress in WD-fed mice $(87 \%)(P=0.0005)$. WD increased ROS production in hearts from ER $\alpha$-deficient mice (Figure 6D) $(P=0.0005)$. Polyphenols was still effective in reducing ROS production by $73 \%$ in hearts taken from ER $\alpha$-deficient mice fed with WD $(P=0.0001)$. These data suggest that polyphenols exerts a protective effect against oxidative stress in the heart independently of the presence of $\operatorname{ER} \alpha$.

Reactive oxygen species production was greater in visceral adipose tissue taken from WD-fed mice compared to SD in WT mice $(P=0.04)$ (Figure 6E). Polyphenols did not modify ROS levels in WT SD mice; however, it completely prevented oxidative stress induced by WD (68.5\%) $(P=0.0029)$ (Figure 6E). In KO mice, WD did not significantly increase ROS production compared to SD. Polyphenols tended to enhance oxidative stress in SD mice $(62.5 \%)$, but it significantly $(P=0.0471)$ decreased ROS levels in WD-fed mice (65.8\%). These results suggest that in visceral adipose tissue polyphenols reduced oxidative stress independently of $\mathrm{ER} \alpha$. 


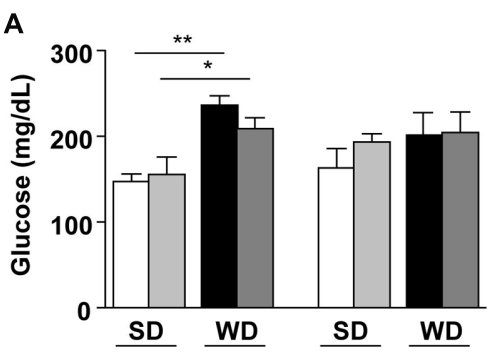

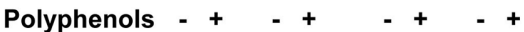

WT

C

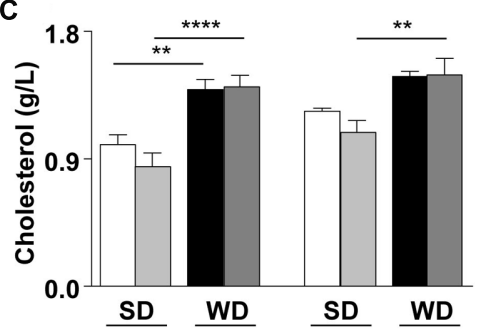

Polyphenols $\begin{array}{llll}-+ & + & + & +\end{array}$

KO

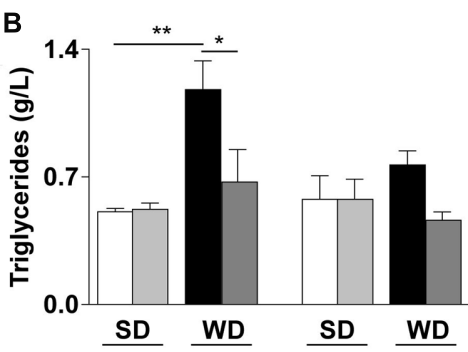

Polyphenols $\frac{-+ \pm+}{\text { WT }} \quad \frac{-+-+}{\text { KO }}$

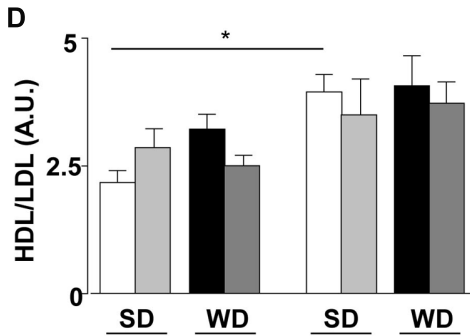

Polyphenols

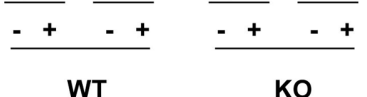

FIGURE 2 | (A) Glucose, (B) triglycerides, (C) cholesterol plasma levels and (D) HDL/LDL ratio of ER $\alpha$ WT and KO mice receiving normal diet (SD), western diet (WD), or SD and WD containing polyphenols (SD + polyphenols and WD + polyphenols, respectively) during 12 weeks. The data are given as the mean \pm SEM. Statistical analyses were performed by one-way ANOVA and Holm-Sidak's post hoc test, ${ }^{*} P<0.05,{ }^{* *} P<0.01,{ }^{* * * *} P<0.0001$.
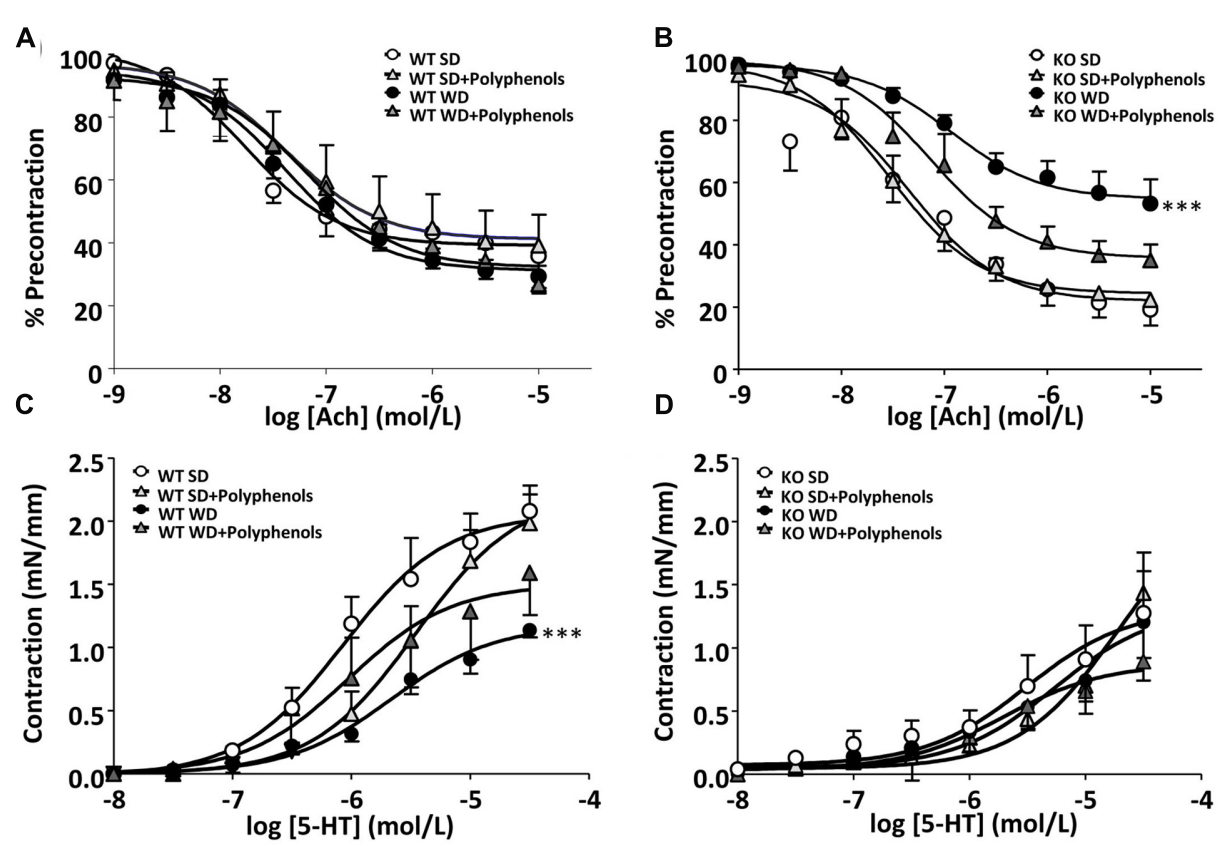

FIGURE 3 | Concentration-response curves to (A,B) Ach and (C,D) 5-HT in aortic rings from ER $\alpha$ WT (A,C) and KO (B,D) mice receiving normal diet (SD), western diet (WD), or SD and WD containing polyphenols (SD + polyphenols and WD + polyphenols, respectively) during 12 weeks. The data are expressed as the mean \pm SEM. Statistical analyses were performed by one-way ANOVA and Holm-Sidak's post hoc test, ${ }^{* * *} P<0.001$. 
TABLE 2 | Cardiac function following 12 weeks of diets.

\begin{tabular}{|c|c|c|c|c|c|c|c|c|}
\hline & \multicolumn{4}{|c|}{ WT } & \multicolumn{4}{|c|}{ KO } \\
\hline & $S D$ & $S D+$ Polyphenols & WD & WD + Polyphenols & $S D$ & $S D+$ Polyphenols & WD & WD + Polyphenols \\
\hline LVEDD (mm) & $3.5 \pm 0.2$ & $3.4 \pm 0.2$ & $3.7 \pm 0.2$ & $3.6 \pm 0.1$ & $3.4 \pm 0.1$ & $3.3 \pm 0.1$ & $3.2 \pm 0.1$ & $3.6 \pm 0.2$ \\
\hline LVESD (mm) & $2.2 \pm 0,1$ & $2.2 \pm 0.2$ & $2.6 \pm 0.2$ & $2.3 \pm 0.1$ & $2.1 \pm 0.1$ & $2.4 \pm 0.1$ & $1.8 \pm 0.1$ & $2.6 \pm 0.2$ \\
\hline EF (\%) & $69.1 \pm 2.8$ & $70.9 \pm 3.6$ & $69.6 \pm 2.8$ & $66.4 \pm 2.2$ & $70.4 \pm 1.1$ & $60.8 \pm 2.2$ & $74.7 \pm 2.3$ & $65.1 \pm 4.4$ \\
\hline $\mathrm{COI}(\mathrm{mL} / \mathrm{min} / \mathrm{g})$ & $0.8 \pm 0.05$ & $0.7 \pm 0.07$ & $0.7 \pm 0.1$ & $0.7 \pm 0.05$ & $0.8 \pm 0.1$ & $0.6 \pm 0.1$ & $0.8 \pm 0.2$ & $0.6 \pm 0.03$ \\
\hline
\end{tabular}

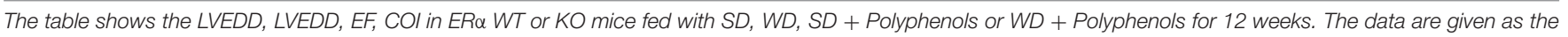
mean \pm SEM.
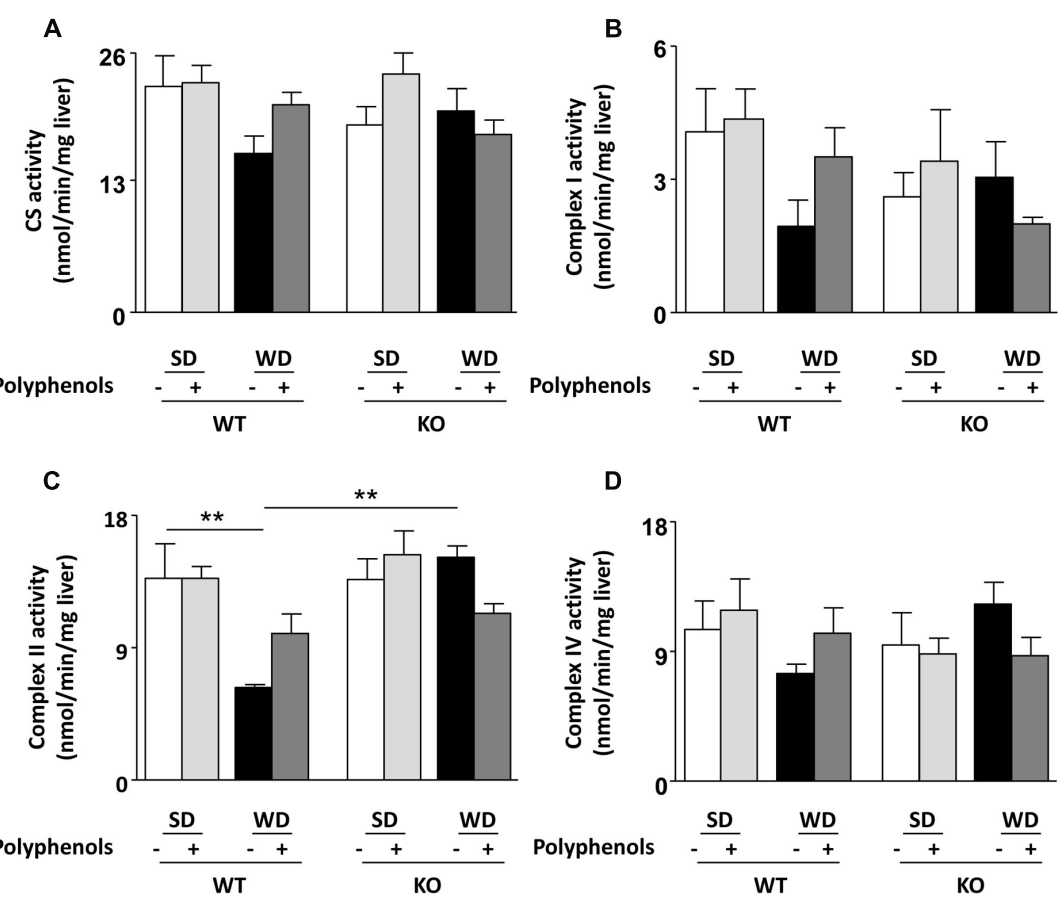

FIGURE 4 | Measurement of (A-D) enzymatic activities of mitochondrial respiratory chain complexes (CS, I, II, IV) in liver from ER $\alpha$ WT and KO mice receiving normal diet (SD), western diet (WD), or SD and WD containing polyphenols (SD + polyphenols and WD + polyphenols, respectively) during 12 weeks. The data are expressed as the mean \pm SEM. Statistical analyses were performed by one-way ANOVA and Holm-Sidak's post hoc test, ${ }^{\star \star} P<0.01$.

In WT mice, WD significantly $(P=0.0007)$ increased ROS production in subcutaneous adipose tissue $(86.7 \%)$ mice compared to SD mice (Figure 6F). ROS level was significantly $(P=0.0007)$ reduced upon polyphenol treatment $(83 \%)$. In KO mice, polyphenols completely prevented (82.3\%) WDinduced ROS production $(P=0.0463)$. These data suggest that polyphenols prevented oxidative stress in subcutaneous adipose tissue independently of ER $\alpha$.

In WT mice, liver ROS production was greater (64\%) in those fed with WD compared to SD $(P=0.0094)$ (Figure 6G). Polyphenols had no effect on SD-fed WT mice; however, it significantly reduced oxidative stress $(82 \%)$ in WD-fed WT animals $(P=0.0006)$. ROS levels were not significantly different in WT and KO mice fed with SD. Polyphenols did not affect ROS production in both SD-fed and WD-fed KO mice. These data suggest that polyphenols prevented oxidative stress in liver dependently of $\mathrm{ER} \alpha$.

\section{DISCUSSION}

This study provides new and interesting evidence for the beneficial effects of polyphenols on metabolic and cardiovascular disorders induced by WD. First, polyphenols significantly improved features of metabolic disorders induced by WD including reduction of visceral and subcutaneous adipose tissue accumulation and plasma triglyceride levels in WT mice. Second, polyphenols increased $\mathrm{NO}^{\bullet}$ bioavailability resulting from both enhanced $\mathrm{NO}^{\bullet}$ production and decreased ROS levels $\mathrm{i} \mathrm{n}$ the aorta and liver. Third, polyphenols decreased oxidative stress in visceral and subcutaneous adipose tissues and heart. Fourth, deletion of $\mathrm{ER} \alpha$ prevented the beneficial effects induced by supplementation with polyphenols in WD-fed mice. Indeed, we clearly demonstrated that the reduction of adiposity, and $\mathrm{NO}^{\bullet}$ bioavailability, as well as, the improved activity of some hepatic mitochondrial complexes 

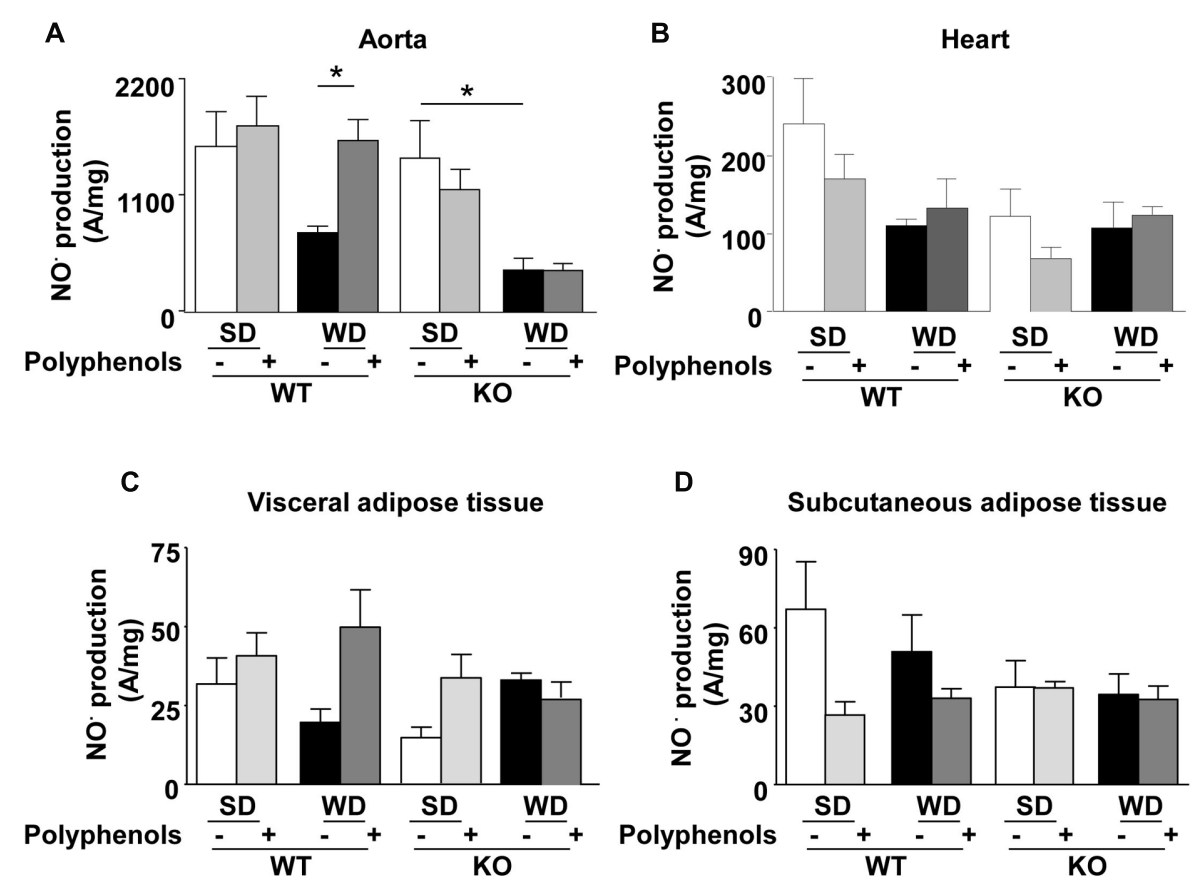

D
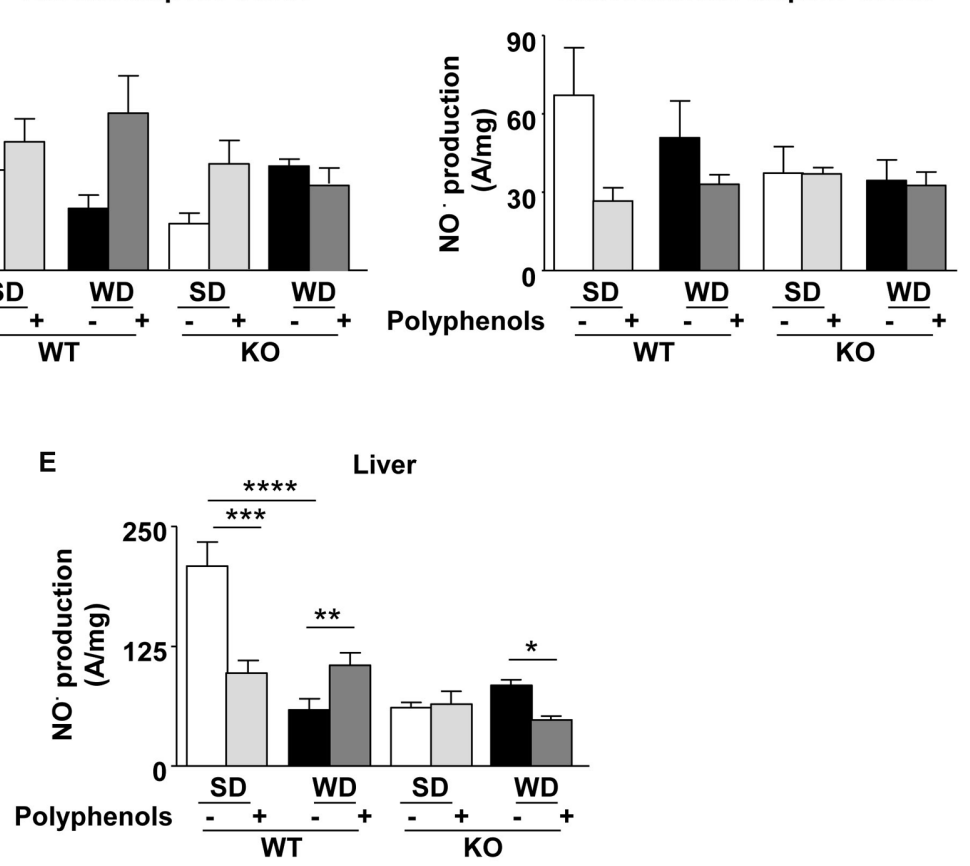

FIGURE 5 | Measurement of in situ NO• productions by electron paramagnetic resonance in aorta (A), heart (B), visceral (C) and subcutaneous (D) adipose tissue, and liver (E) from ER $\alpha$ WT and KO mice receiving normal diet (SD), western diet (WD), or SD and WD containing polyphenols during 12 weeks. The data are expressed as the mean \pm SEM. Statistical analyses were performed by one-way ANOVA and Holm-Sidak's post hoc test, ${ }^{*} P<0.05,{ }^{* *} P<0.01$, *** $P<0.001$

are mediated via an ER $\alpha$-dependent mechanism. On the other hand, deletion of $\mathrm{ER} \alpha$ had no effect on the ability of polyphenols to decrease oxidative stress and the accumulation of subcutaneous adipose tissue, and to reduce oxidative stress of in the visceral adipose tissue and heart from mice fed with WD.

As expected, WD increased body weight gain more than SD. This is associated with increased fat accumulation, plasma glucose, triglycerides and cholesterol levels. Additionally, it caused oxidative stress in vascular, cardiac, adipose and hepatic tissues.

Here, we showed that polyphenols were not able to significantly decrease weight gain. This finding concurs with a parallel study using the same experimental protocol on mice treated with polyphenols from grape seed (unpublished results) and a previous study on Zucker fatty rats treated with polyphenols extract at the dose of $20 \mathrm{mg} / \mathrm{kg} /$ day during 8 weeks (Agouni et al., 2009). Furthermore, 6 weeks of highfructose diet and simultaneous administration of $50 \mathrm{mg} / \mathrm{kg} / \mathrm{day}$ or $21 \mathrm{mg} / \mathrm{kg} /$ day of the same composition of polyphenols did not modify rat body weight (Al-Awwadi et al., 2004, 2005). Here, we have shown that polyphenols decreased adiposity in particular visceral adipose tissue accumulation, in WT mice. Dietary polyphenols may exert their effects on adipose tissue through one or more signaling and transcriptional pathways potentially including those mediated by NF- $\kappa$, AMPK, PPAR $\gamma$, and PGC-1 $\alpha$ (Wang et al., 2014). Among the classes of polyphenols contained in red wine, flavan-3-ols, flavonols and antocyanins have been described to act on adipose tissue. Notably catechins, especially EGCG, have an anti-adipogenic 


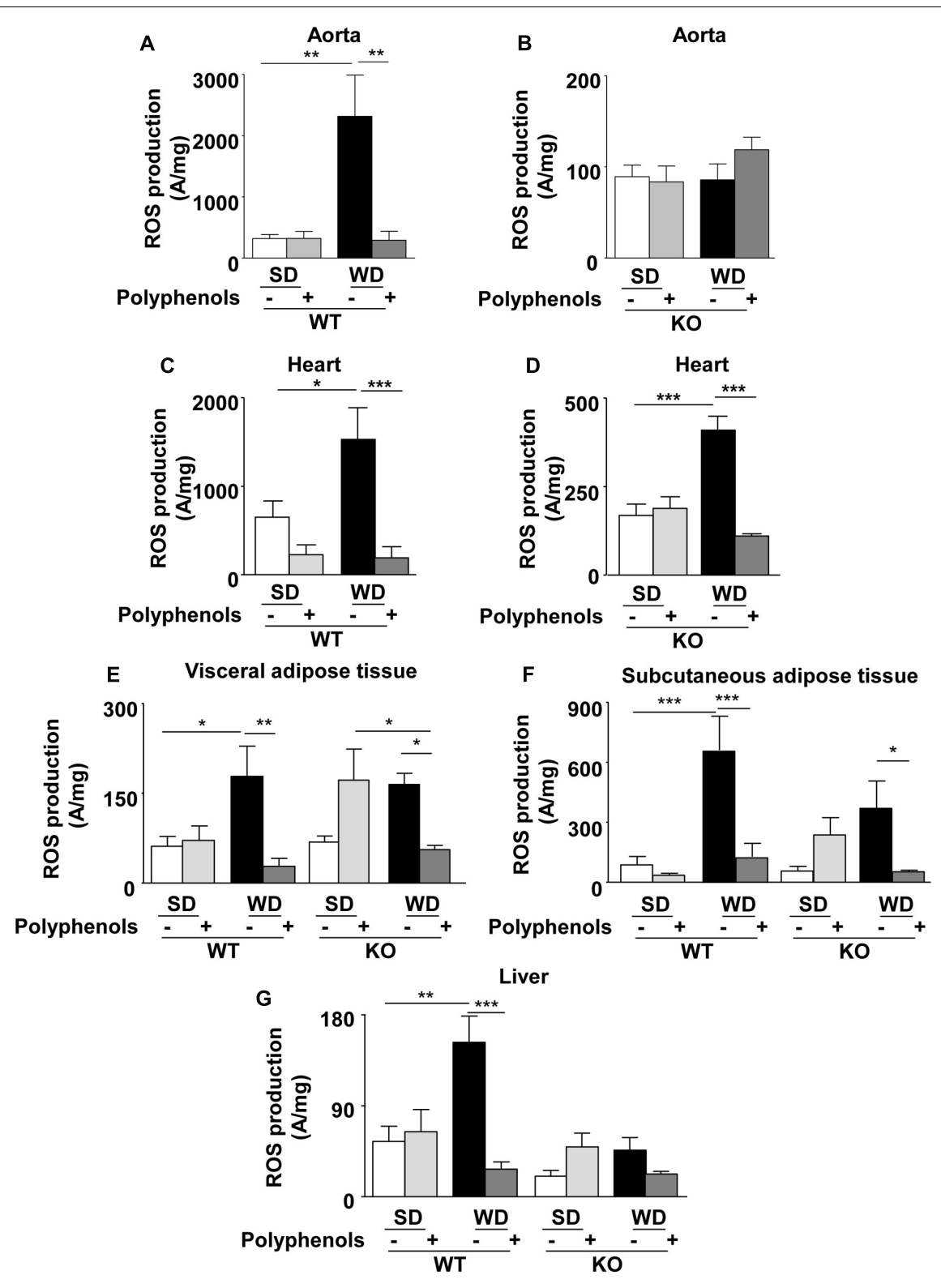

FIGURE 6 | Measurement of in situ ROS productions by electron paramagnetic resonance in aorta (A,B), heart (C,D), visceral (E) and subcutaneous (F) adipose tissue, and liver (G) from ER $\alpha$ WT and KO mice receiving normal diet (SD), western diet (WD), or SD and WD containing polyphenols during 12 weeks. The data are expressed as the mean \pm SEM. Statistical analyses were performed by one-way ANOVA and Holm-Sidak's post hoc test, ${ }^{*} P<0.05$, ${ }^{*} P<0.01$, $* * * P<0.001$.

effect via ERK- and CDK-dependent signaling pathway, as well as activation of AMPK and inhibition of lipogenic enzymes (Moon et al., 2007). The flavanols, quercetin and anthocyanins (both at $0.01 \mathrm{~mol} / \mathrm{kg}$ diet), decreased mesenteric adipose tissue weight in mice fed a high-fat diet for 12 weeks (Hoek-van den Hil et al., 2015). Accordingly, the proposed mechanism underlying the anti-obesity effect exhibited by anthocyanins was mainly mediated by inhibition of preadipocyte proliferation and lipid accumulation during differentiation and reduction of basal lipolysis in 3T3-L1 cells (Kim et al., 2012).
The present study also demonstrated that polyphenols decreased triglyceride plasma levels, which was already reported (Agouni et al., 2009). The extracts used in both studies shared five classes of polyphenols (flavan-3-ols, hydroxycinnamic acids, flavonols, anthocyanins and proanthocyanidins). It can be hypothesized that these classes of polyphenols trigger the decrease of triglyceridemia.

With regards to cardiac function, mice receiving WD did not develop obesity-induced ventricular hypertrophy and diastolic dysfunction as evidenced by echocardiography evaluations. This was in accordance with a previous study showing that mice fed 


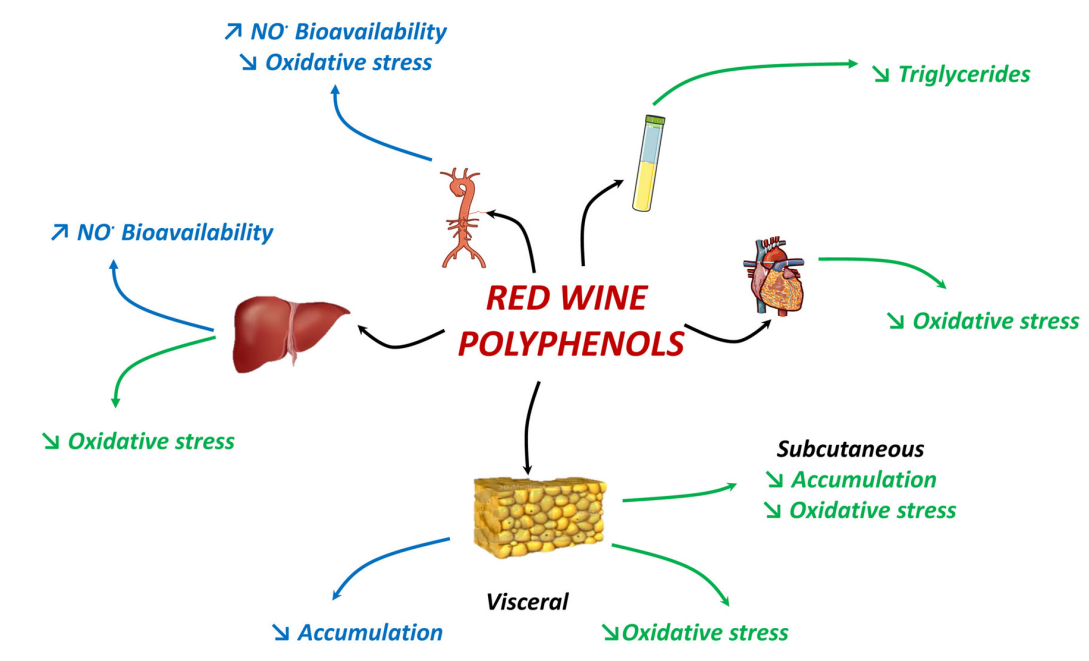

ER $\alpha$ dependent

ER $\alpha$ independent

\section{$\searrow$ Metabolic and cardiovascular alteration linked to WD}

FIGURE 7 | In WD-fed mice, dietary supplementation with polyphenols reduced aortic ROS, enhanced NO• bioavailability in aorta and liver; and reduced visceral adipose tissue accumulation via an $\mathrm{ER} \alpha$-dependent mechanism. Polyphenols decreased plasma triglycerides, subcutaneous fat accumulation and ROS in adipose tissues, liver and heart independent of $E R \alpha$. Hence, effects generated by polyphenols attenuate most features of metabolic dysfunctions partially via $\mathrm{ER} \alpha$.

with high-fat diet were unable to recapitulate defects in cardiac function (Brainard et al., 2013). It is possible that the model used in this study represents an early stage of cardiac disease, without the onset of irreversible damage due to hypertrophy or cardiac failure. Although polyphenols did not significantly modify the decreased of cardiac $\mathrm{NO}^{\bullet}$ production, it improved WD-induced oxidative stress. Also, in a rat model of metabolic syndrome, polyphenols such as catechin, resveratrol, delphinidin, and gallic acid prevent cardiac ROS overproduction and NADPH overexpression (for review see Le Lay et al., 2014). Moreover, ROS reduction could be explained by the intrinsic capacity of polyphenols to scavenge ROS or alternatively by their ability to modulate expression and activity of antioxidant enzymes.

With regard to vascular function, although polyphenols did not alter responses to Ach and 5-HT, it enhanced $\mathrm{NO}^{\bullet}$ production and reduced superoxide anions in aortas leading to increase $\mathrm{NO}^{\bullet}$ bioavailability, a notion compatible with our previous data in Zucker fatty rats (Agouni et al., 2009). Indeed, polyphenols were able to enhance $\mathrm{NO}^{\bullet}$ bioavailability in aortas from Zucker fatty rats resulting from increased $\mathrm{NO}^{\bullet}$ production through enhanced endothelial NOS activity and reduced superoxide anion release via decreased expression of NADPH oxidase membrane sub-unit, Nox-1 (Agouni et al., 2009).

In subcutaneous and visceral adipose tissues, polyphenols were able to completely prevent oxidative stress induced by WD without a significant effect on $\mathrm{NO}^{\bullet}$ level. In line with these results, flavonoids such as quercetin, epicatechin and procyanidins, and phenolic acids protect 3T3-L1 preadipocytes from ROS production by enhancing superoxide dismutase antioxidant enzyme gene expression (Marimoutou et al., 2015).
Furthermore, current reports show that polyphenols were able to correct hepatic abnormalities described in obesity, such as impaired $\mathrm{NO}^{\bullet}$ production, mitochondrial energy metabolism (Holmstrom et al., 2012) and exaggerated oxidative stress. Emerging evidence suggests that oxidative stress and altered redox balance play a crucial part in the pathogenesis of obesityrelated hepatic complications, including steatosis, steatohepatitis and fibrosis, all involving mitochondrial dysfunction. Alterations in the oxidative phosphorylation pathways in liver mitochondria have been reported in various models of obesity with some conflicting results concerning respiratory chain complex (Crescenzo et al., 2008; Vial et al., 2011). It has been shown that dietary supplementation with curcumin diminished mitochondrial dysfunction in the liver of $d b / d b$ mice. This is likely to be due to decreasing lipid peroxidation, resulting in an increase in ATPase activity, restoration of oxygen consumption and $\mathrm{NO}^{\bullet}$ synthesis (Soto-Urquieta et al., 2014). It has been reported that high-fat diet affected the activity of all complexes of the respiratory chain in mouse liver (Mingorance et al., 2012). Our results are consistent with the latter at least with the reduced activity of complex II associated with a non-significant decrease of CS activity, supporting either an intrinsic mitochondrial dysfunction or a lower mitochondrial number. Whatever the correct explanation, it is important to note that treatment with polyphenols led to a correction of hepatic complex II activity, as well as $\mathrm{NO}^{\bullet}$ and ROS production.

Here, we provide evidence that the alpha isoform of ER participates in the protective in vivo effects of polyphenols against WD-induced metabolic defects especially on vascular and liver nitrative stresses and visceral adiposity. It is well 
known that estrogenic signaling prevents accumulation of visceral fat, increases central sensitivity to leptin, increases the expression of insulin receptors in adipocytes, and decreases the lipogenic activity of lipoprotein lipase in adipose tissue, thus preventing the development of obesity and insulin resistance (Clegg et al., 2006). Accordingly, lowering of adiposity and visceral fat mass accumulation, improvement of vascular function and $\mathrm{NO}^{\bullet}$ bioavailability are mediated via an ER $\alpha$-dependent mechanism. This notion is congruent with previous data showing that polyphenols compounds exert vascular protection and that this effect requires $\mathrm{ER} \alpha$ (Chalopin et al., 2010).

Taken together, these results reveal a scenario in which supplementation of polyphenols during a WD exerts an integrative response able to attenuate most features of metabolic dysfunctions; it also underscores the importance of $\mathrm{ER} \alpha$ activation on some of these protective effects including vascular and liver nitrative stresses and visceral adiposity (Figure 7). Furthermore, it highlights an additional mechanism of polyphenols to reduce oxidative stress in different tissues involved in obesity-related disorders. Therefore, this study points to the therapeutic potential of red wine extract in metabolic and cardiovascular alterations linked to excessive energy intake.

\section{AUTHOR CONTRIBUTIONS}

RA conceived the experiments; RA and MM designed the experiments; DL, RS, NC, LV, CJ and LD performed

\section{REFERENCES}

Agouni, A., Lagrue-Lak-Hal, A., Mostefai, H. A., Tesse, A., Mulder, P., Rouet, P., et al. (2009). Red wine polyphenols prevent metabolic and cardiovascular alterations associated with obesity in Zucker fatty rats (Fa/Fa). PLoS ONE 4:e5557. doi: 10.1371/journal.pone.0005557

Al-Awwadi, N. A., Araiz, C., Bornet, A., Delbosc, S., Cristol, J. P., Linck, N., et al. (2005). Extracts enriched in different polyphenolic families normalize increased cardiac NADPH oxidase expression while having differential effects on insulin resistance, hypertension, and cardiac hypertrophy in high-fructose-fed rats. J. Agric. Food Chem. 53, 151-157. doi: 10.1021/jf048919f

Al-Awwadi, N. A., Bornet, A., Azay, J., Araiz, C., Delbosc, S., Cristol, J. P., et al. (2004). Red wine polyphenols alone or in association with ethanol prevent hypertension, cardiac hypertrophy, and production of reactive oxygen species in the insulin-resistant fructose-fed rat. J. Agric. Food Chem. 52, 5593-5597. doi: $10.1021 /$ jf049295g

Andriambeloson, E., Kleschyov, A. L., Muller, B., Beretz, A., Stoclet, J. C., and Andriantsitohaina, R. (1997). Nitric oxide production and endotheliumdependent vasorelaxation induced by wine polyphenols in rat aorta. $B r . J$. Pharmacol. 120, 1053-1058. doi: 10.1038/sj.bjp.0701011

Andriambeloson, E., Magnier, C., Haan-Archipoff, G., Lobstein, A., Anton, R., Beretz, A., et al. (1998). Natural dietary polyphenolic compounds cause endothelium-dependent vasorelaxation in rat thoracic aorta. J. Nutr. 128, 2324-2333.

Andriantsitohaina, R., Auger, C., Chataigneau, T., Étienne-Selloum, N., Li, H., Martínez, M. C., et al. (2012). Molecular mechanisms of the cardiovascular protective effects of polyphenols. Br. J. Nutr. 108, 1532-1549. doi: 10.1017/ S0007114512003406

Baron-Menguy, C., Bocquet, A., Guihot, A. L., Chappard, D., Amiot, M. J., Andriantsitohaina, R., et al. (2007). Effects of red wine polyphenols on postischemic neovascularization model in rats: low doses are proangiogenic, high doses anti-angiogenic. FASEB J. 21, 3511-3521. doi: 10.1096/fj.06$7782 \mathrm{com}$ the experiments; DL, RS, NC, CJ, and LD acquired data; DL, RS, NC analyzed data; CD managed financial and administrative tasks; RS, MM, and RA interpreting and discussed the results; RS, MM, and RA wrote and revised the manuscript. All authors read and approved the final manuscript.

\section{FUNDING}

This work was supported by grant of “OSEO” (bpiFrance).

\section{ACKNOWLEDGMENTS}

We are grateful to $M$. Wertheimer and SCAHU staff (University of Angers) for taking care of animals, Dr. V. Thepot Seegers (University of Angers) for help in statistical analysis, Dr. S. Piper (NHLI, Imperial College, London) for a careful reading of the manuscript and for correcting the English.

\section{SUPPLEMENTARY MATERIAL}

The Supplementary Material for this article can be found online at: http://journal.frontiersin.org/article/10.3389/fphar. 2016.00529/full\#supplementary-material

Bernátová, I., Pechánová, O., Babál, P., Kyselá, S., Stvrtina, S., and Andriantsitohaina, R. (2002). Wine polyphenols improve cardiovascular remodeling and vascular function in $\mathrm{NO}^{\bullet}$-deficient hypertension. Am. J. Physiol. Heart Circ. Physiol. 282, H942-H948. doi: 10.1152/ajpheart.00724.2001

Bowers, J. L., Tyulmenkov, V. V., Jernigan, S. C., and Klinge, C. M. (2000). Resveratrol acts as a mixed agonist/antagonist for estrogen receptors $\alpha$ and $\beta$. Endocrinology 141, 3657-3667. doi: 10.1210/endo.141.10.7721

Brainard, R. E., Watson, L. J., Demartino, A. M., Brittian, K. R., Readnower, R. D., Boakye, A. A., et al. (2013). High fat feeding in mice is insufficient to induce cardiac dysfunction and does not exacerbate heart failure. PLoS ONE 2013:e83174. doi: 10.1371/journal.pone.0083174

Chalopin, M., Soleti, R., Benameur, T., Tesse, A., Faure, S., Martínez, M. C., et al. (2014). Red wine polyphenol compounds favor neovascularisation through estrogen receptor $\alpha$-independent mechanism in mice. PLoS ONE 9:e110080. doi: 10.1371/journal.pone.0110080

Chalopin, M., Tesse, A., Martínez, M. C., Rognan, D., Arnal, J. F., and Andriantsitohaina, R. (2010). Estrogen receptor alpha as a key target of red wine polyphenols action on the endothelium. PLOS ONE 5:e8554. doi: 10.1371/ journal.pone.0008554

Clegg, D. J., Brown, L. M., Woods, S. C., and Benoit, S. C. (2006). Gonadal hormones determine sensitivity to central leptin and insulin. Diabetes Metab. Res. Rev. 55, 978-987.

Covas, M. I., Gambert, P., Fitó, M., and de la Torre, R. (2010). Wine and oxidative stress: up-to-date evidence of the effects of moderate wine consumption on oxidative damage in humans. Atherosclerosis 208, 297-304. doi: 10.1016/j. atherosclerosis.2009.06.031

Crescenzo, R., Bianco, F., Falcone, I., Prisco, M., Liverini, G., and Iossa, S. (2008). Alterations in hepatic mitochondrial compartment in a model of obesity and insulin resistance. Obesity (Silver Spring) 16, 958-964. doi: 10.1038/oby.2008.10

Curin, Y., Ritz, M. F., and Andriantsitohaina, R. (2006). Cellular mechanisms of the protective effect of polyphenols on the neurovascular unit in strokes. Cardiovasc. Hematol. Agents Med. Chem. 4, 277-288. doi: 10.2174/ 187152506778520691 
Diebolt, M., Bucher, B., and Andriantsitohaina, R. (2001). Wine polyphenols decrease blood pressure, improve $\mathrm{NO}^{\bullet}$ vasodilatation, and induce gene expression. Hypertension 38, 159-165. doi: 10.1161/01.HYP.38.2.159

Hoek-van den Hil, E. F., van Schothorst, E. M., van der Stelt, I., Swarts, H. J., van Vliet, M., Amolo, T., et al. (2015). Direct comparison of metabolic health effects of the flavonoids quercetin, hesperetin, epicatechin, apigenin and anthocyanins in high-fat-diet-fed mice. Genes Nutr. 10:469. doi: 10.1007/s12263-015-0 469-z

Holmstrom, M. H., Iglesias-Gutierrez, E., Zierath, J. R., and Garcia-Roves, P. M. (2012). Tissue-specific control of mitochondrial respiration in obesityrelated insulin resistance and diabetes. Am. J. Physiol. Endocrinol. Metab. 302, E731-E739. doi: 10.1152/ajpendo.00159.2011

Kim, H. K., Kim, J. N., Han, S. N., Nam, J. H., Na, H. N., and Ha, T. J. (2012). Black soybean anthocyanins inhibit adipocyte differentiation in 3T3-L1 cells. Nutr. Res. 32, 770-777. doi: 10.1016/j.nutres.2012.06.008

Le Lay, S., Simard, G., Martinez, M. C., and Andriantsitohaina, R. (2014). Oxidative stress and metabolic pathologies: from an adipocentric point of view. Oxid. Med. Cell. Longev. 2014:908539. doi: 10.1155/2014/908539

Marimoutou, M., Le Sage, F., Smadja, J., Lefebvre d'Hellencourt, C., Gonthier, M. P., and Robert-Da Silva, C. (2015). Antioxidant polyphenol-rich extracts from the medicinal plants Antirhea borbonica, Doratoxylon apetalum and Gouania mauritiana protect 3T3-L1 preadipocytes against $\mathrm{H} 2 \mathrm{O} 2$, TNF $\alpha$ and LPS inflammatory mediators by regulating the expression of superoxide dismutase and NF-кB genes. J. Inflamm. (Lond.) 2:10. doi: 10.1186/s12950-0150055-6

Mingorance, C., Duluc, L., Chalopin, M., Simard, G., Ducluzeau, P. H., Herrera, M. D., et al. (2012). Propionyl-L-carnitine corrects metabolic and cardiovascular alterations in diet-induced obese mice and improves liver respiratory chain activity. PLOS ONE 7:e34268. doi: 10.1371/journal.pone. 0034268

Moon, H. S., Lee, H. G., Choi, Y. J., Kim, T. G., and Cho, C. S. (2007). Proposed mechanisms of (-)-epigallocatechin-3-gallate for anti-obesity. Chem. Biol. Interact. 67, 85-98. doi: 10.1016/j.cbi.2007.02.008
Musatov, S., Chen, W., Pfaff, D. W., Mobbs, C. V., Yang, X. J., Clegg, D. J., et al. (2007). Silencing of estrogen receptor alpha in the ventromedial nucleus of hypothalamus leads to metabolic syndrome. Proc. Natl. Acad. Sci. U.S.A. 104, 501-506. doi: 10.1073/pnas.0610787104

Pechanova, O., Rezzani, R., Babal, P., Bernatova, I., and Andriantsitohaina, R. (2006). Beneficial effects of Provinols: cardiovascular system and kidney. Physiol. Res. 55, S17-S30.

Soto-Urquieta, M. G., López-Briones, S., Pérez-Vázquez, V., Saavedra-Molina, A., González-Hernández, G. A., and Ramírez-Emiliano, J. (2014). Curcumin restores mitochondrial functions and decreases lipid peroxidation in liver and kidneys of diabetic db/db mice. Biol. Res. 47:74. doi: 10.1186/0717-6287-47-74

Vial, G., Dubouchaud, H., Couturier, K., Cottet-Rousselle, C., Taleux, N., Athias, A., et al. (2011). Effects of a high-fat diet on energy metabolism and ROS production in rat liver. J. Hepatol. 54, 348-356. doi: 10.1016/j.jhep.2010.06.044

Wang, S., Moustaid-Moussa, N., Chen, L., Mo, H., Shastri, A., Su, R., et al. (2014). Novel insights of dietary polyphenols and obesity. J. Nutr. Biochem. 25, 1-18. doi: 10.1016/j.jnutbio.2013.09.001

Xu, Y., Nedungadi, T. P., Zhu, L., Sobhani, N., Irani, B. G., Davis, K. E., et al. (2011). Distinct hypothalamic neurons mediate estrogenic effects on energy homeostasis and reproduction. Cell Metab. 14, 453-465. doi: 10.1016/j.cmet. 2011.08.009

Conflict of Interest Statement: The authors declare that the research was conducted in the absence of any commercial or financial relationships that could be construed as a potential conflict of interest.

Copyright (c) 2017 Leonetti, Soleti, Clere, Vergori, Jacques, Duluc, Dourguia, Martínez and Andriantsitohaina. This is an open-access article distributed under the terms of the Creative Commons Attribution License (CC BY). The use, distribution or reproduction in other forums is permitted, provided the original author(s) or licensor are credited and that the original publication in this journal is cited, in accordance with accepted academic practice. No use, distribution or reproduction is permitted which does not comply with these terms. 